\title{
EFFECT ON STRUCTURED TEACHING PROGRAMME REGARDING CARDIOPULMONARY RESUSCITATION ON KNOWLEDGE AND PRACTICE AMONG ADOLESCENTS
}

\section{Mr. Priyankatt Bhatt}

Abstract

With a view to assess the effectiveness of structured teaching programme on cardiopulmonary resuscitation, a quasi experimental study with a evaluative approach was undertaken on 60 adolescents. Simple random sampling technique was used in selecting adolescents. Prior to implementation of structured teaching programme the adolescents had poor knowledge and practice regarding CPR, whereas after implementation of structured teaching programme the adolescent's knowledge and practice regarding CPR significantly improved with the difference of mean percentage revealing effectiveness of structured teaching programme.

Keywords : Structured teaching programme, Cardiopulmonary Resuscitation Adolescence.

\section{Introduction}

Cardiac Arrest is a major emergency situation faced by the people it requires emergency intervention in terms of resuscitation by using advanced practice called cardio pulmonary resuscitation. As children grow they must learn not only to cope with current demand but also to prepare for many unexpected event to facing tomorrow.

CPR combines rescue breathing and chest compressions. Rescue breathing provides oxygen to the persons lungs. Chest compressions keep oxygen-rich blood circulating until an effective heartbeat and breathing can be restored. Time is very important when dealing with an unconscious person who is not breathing. Permanent brain damage beings after only 4 minutes without oxygen, and death can occur as soon as 4-6 minutes later.

It is during those critical minutes that cardio pulmonary resuscitation can provide oxygenated blood to the victim brain and the heart, dramatically increasing his chance of survival and if properly instructed almost anyone can learn and perform CPR.

Children under 15 year comprise nearly $40 \%$ of the total population. Childhood injuries are very common and comprise the base of the injury pyramid for all ages. Globally, more than 39,000 
children per day or 14 million children per year require medical attention for accidental injuries. Childhood injuries, mainly accidental injuries are the leading cause of death among children between 5-14 years of age.

Objectives of the Study

1. To assess the pre test and post test knowledge level of adolescents regarding CPR.

2. To assess the pre test and post test practice level of adolescents regarding CPR.

3. To evaluate the effectiveness of STP on knowledge and practice of adolescents regarding CPR.

4. To find out relationship between post test knowledge and practice of adolescents regarding CPR.

5. To find out the association between post test knowledge score and selected demographic variables.

6. To find out the association between post test practice score and selected demographic variables.

\section{Hypothesis}

- H1 - There is a significant difference between pre test knowledge and practice of adolescents than post test knowledge and practice.
- $\mathrm{H} 2-$ There is a significant relationship between post test knowledge and practice of adolescents.

- $\mathrm{H} 3$ - There is a significant association between post test knowledge score and selected demographic variables.

- H4 - There is a significant association between post test practice score and selected demographic variables.

\section{Materials and Methods}

Quasi experimental design on group pre-test, post-test with evaluative approach was used. Structured questionnaire and observational checklist was prepared that was focusing on structured teaching programme. Reliability of the tool was tested and validity was ensured in consultation with guides and experts in the field of medicines and nursing. The study was carried out in Sanskaar school at Piparia, Vadodara. 60 adolescents were selected by simple random sampling technique, structured questionnaire and observations checklist was used to collect the needed data. Collected data was analyzed by using descriptive and inferential statistics. 


\section{Results and discussion}

Comparison of pretest and post test practice scores regarding CPR $\mathrm{N}=60$

\begin{tabular}{|l|l|l|l|l|}
\hline \multirow{2}{*}{\multicolumn{1}{c|}{$\begin{array}{c}\text { Practice } \\
\text { Aspects }\end{array}$}} & \multicolumn{4}{c|}{ Response } \\
\cline { 2 - 5 } & \multicolumn{2}{|c|}{ Pretest } & \multicolumn{2}{c|}{ Post test } \\
\cline { 2 - 5 } & N & $\%$ & N & $\%$ \\
\hline $\begin{array}{l}\text { Unfavorable 0- } \\
4\end{array}$ & 43 & 71.6 & 4 & 66 \\
\hline Favourable 5-7 & 17 & 28.3 & 15 & 25 \\
\hline $\begin{array}{l}\text { Most } \\
\text { Favorable 8-10 }\end{array}$ & 0 & 0 & 41 & 68.3 \\
\hline Total & 60 & 100 & 60 & 100 \\
\hline
\end{tabular}

Comparison of Pre test and post test knowledge scores Regarding CPR

\begin{tabular}{|l|l|l|l|l|c|}
\hline \multirow{2}{*}{$\begin{array}{l}\text { Practice } \\
\text { Aspects }\end{array}$} & \multirow{2}{*}{$\begin{array}{l}\text { Knowl } \\
\text { edge } \\
\text { Score }\end{array}$} & \multicolumn{3}{|l|}{ Response } \\
\cline { 3 - 6 } & \multicolumn{2}{|l|}{ Pretest } & \multicolumn{2}{l|}{ Post test } \\
\cline { 3 - 6 } & $\mathbf{N}$ & $\mathbf{\%}$ & $\mathbf{N}$ & $\%$ \\
\hline $\begin{array}{l}\text { Unfavorable } \\
(0-35 \%)\end{array}$ & $0-7$ & 36 & 60 & 0 & 0 \\
\hline $\begin{array}{l}\text { Moderately } \\
\text { Adequate } \\
(35-65 \%)\end{array}$ & $8-13$ & 21 & 35 & 13 & 21.66 \\
\hline $\begin{array}{l}\text { Adequate } \\
(06-100 \%)\end{array}$ & $14-20$ & 3 & 5 & 47 & 78.33 \\
\hline Total & & & & & \\
\hline
\end{tabular}

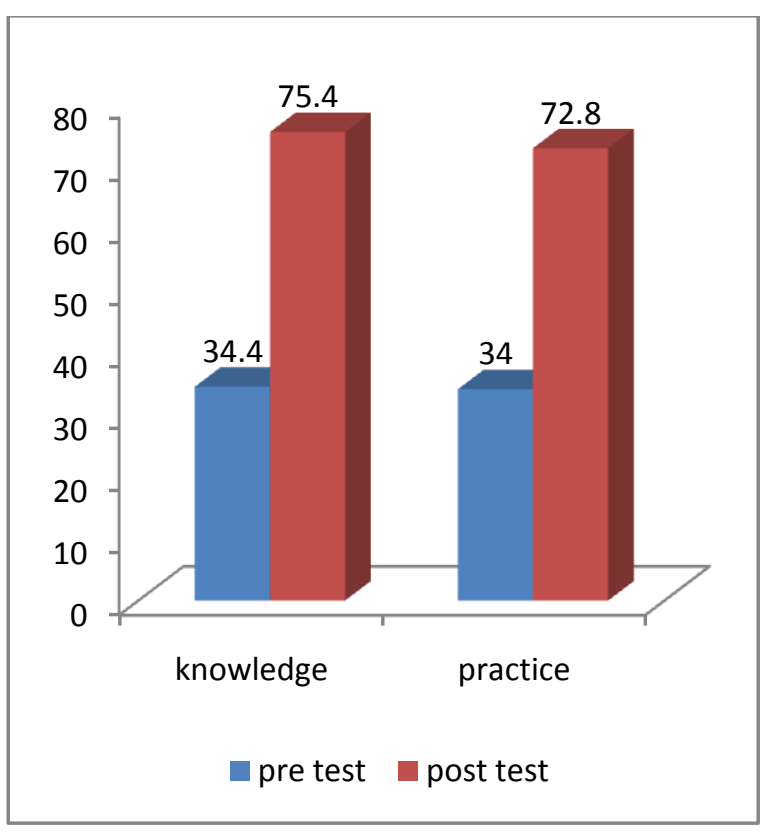

The structured teaching programme was effective in improving the knowledge and practice regarding $\mathrm{CPR}$, hypothesis $\mathrm{H} 1$ is accepted

Relationship between the Post Test Knowledge CPR, Hypothesis H1 is accepted

\begin{tabular}{|c|c|c|c|}
\hline $\begin{array}{l}\text { Sr, } \\
\text { No. }\end{array}$ & Variables & $\begin{array}{l}\text { Correlation } \\
\text { Value }\end{array}$ & $\begin{array}{l}\text { Statistical } \\
\text { Value }\end{array}$ \\
\hline 1. & $\begin{array}{l}\text { Post Test } \\
\text { Knowledge } \\
\text { and post } \\
\text { test } \\
\text { practice } \\
\text { scores }\end{array}$ & $r=0.56$ & $\begin{array}{l}\text { Positive } \\
\text { Correlation }\end{array}$ \\
\hline
\end{tabular}

Correlation Value $(\mathrm{r}=0.56)$ shows that there is positive relationship between post test knowledge and practice score. 
$\mathrm{H} 2$ - there will be significant relationship between post test knowledge and practice of adolescents, hypothesis (H2) is accepted.

\section{Association between selected demographic variables and post test knowledge score}

There was no significant association between post test knowledge score with any demographic variables, hypothesis $(\mathrm{H} 3)$ is rejected.

Associated between selected demographic variables and post test practice score

There was significant association between post test practice score with the occupation of the father of the adolescents, hypothesis (H4) is accepted.

\section{Discussion}

The total mean percentage of knowledge score of the adolescents during pretest means was $34.4 \%$ with and SD was 2.89 and in the post test mean was $75.4 \%$ and SD was 2.43. Where as the total mean percentage of practice was $34 \%$ and SD was 1.45 and in the post test mean was $73 \%$ and SD was 1.71 significant difference was found between pre and post knowledge and practice scores.

The level of practice regarding CPR was assessed and depicted in figures. Out of the 60 adolescents in pre test, 43 (71.6 percent) had unfavorable practice, whose scores ranged below 4 out of 10 about 7 (28.3 percent) had favorable practice, whose scores ranged between 5-7 out of 10 .

In post test 4 adolescents ( 7 percent) had unfavourable practice (0-4 scores), 15 (25 percent) had favorable practice (5-7) and41 (67 percent) had most favorable practice score (8-10). The mean and standard deviation of the results show that the mean 3.40 ( 34 percent) and S.D. 1.45 in pre test and mean 7.28 (73 percent) and S.D. 1.71 in post test are significantly different.

The findings of the study supported by Celenza T, Gennat HC conducted a study on community competence in cardio pulmonary resuscitation. The aim of this study was to determine community application of cardio pulmonary resuscitation practices in an emergency and to assess the value of training programmes in raising community competence. Telephone survey was conducted, the population was chosen randomly, sub sample performed a practical demonstration of CPR practices using manikin as the victim, performance was assessed by two observers using predetermined criteria. The investigator concluded that resuscitation practice and 
knowledge should be refreshed and updated regular.

Comparison of mean, standard deviation and mean percentage of the knowledge score of the pre and post test reveals an increase of 75.4 percent in total mean knowledge score of adolescents. The analysis of the difference in knowledge of adolescents in pre test and post test revealed that there was high significant different 8.19 between pre and post test score of over all knowledge on CPR, analysis of practice score represents that there was high significant difference (3.88) between pre and post test practice score they by, supporting the stated hypothesis that structured teaching programme is effective in improving knowledge on CPR.

The findings of the study supported by Vander Schmidt H, Burnap TK Thwaites $\mathrm{JK}$, conducted a study on evaluation of a cardio pulmonary resuscitation course for secondary schools. Objective of the study was to test the feasibility of teaching secondary school students to perform cardio pulmonary resuscitation. The results suggested that it is possible to train secondary school students to perform the $\mathrm{ABC}$ of $\mathrm{CPR}$ if they have an opportunity to practice these practices.

\section{Limitations}

1. Adolescents who are studying in Sanskar School Piparia.

2. Adolescents willing to participate

3. Adolescents who are present at the time of study.

\section{Conclusion}

The present study was conducted to assess the effectiveness of structured teaching programme on knowledge and practices regarding cardiopulmonary resuscitation among adolescents. In pre-test majority of the adolescents had inadequate knowledge and practice regarding CPR. After structured teaching programme the respondents indicated significant increase in knowledge and practice regarding CPR.

There is an increase need for awareness program and periodical educational sessions for adolescents regarding first aid and CPR training in community to prevent accidental death of children. The child health nurse should take extra care in policy making, planning and organizing the educational session to create awareness on basic life saving measures.

\section{References}

1. John A,. Parakos Cardiopulmonary resuscitation in David L. Brown 
Cardiac intensive care Philadelphia : wb sunders company, 1997, p. 11547.

2. Emergency Cardiovascular Care Committee, Sub Committees, and Task Forces of the American Heart Association. 2005 American Heart Association Guidelines for Cardiopulmonary Resuscitation and Emergency Cardiovascular Care
Ciruclation 2005; 112 (24 Suppl) : IVI - 203.

3. Basic life support (MS-Word) Version Cited 2007 June 2. Available from URL : http://ww.cprtoday.com

4. Park K Park's Text Book of Preventive and Social Medicine, Demography and Family planning $19^{\text {th }}$ edition, 2007 page No. 379-383. 